\title{
LIBBY AND THE INTERDISCIPLINARY ASPECT OF RADIOCARBON DATING
}

Nicole de Messières ${ }^{1}$

4506 Dresden Street, Kensington, Maryland 20895, USA

\begin{abstract}
At a time when exchange between scientific and non-scientific disciplines was uncommon, Willard $\mathrm{F}$ Libby broke through conventional barriers. Early influences prepared him for a career marked by its interdisciplinary approach, and for a discovery with far-ranging applications to many diverse branches of knowledge.
\end{abstract}

\section{INTRODUCTION}

Seldom has a single discovery in chemistry had such an impact on the thinking in so many fields of human endeavour. Seldom has a single discovery generated such wide public interest. -Nobel Committee 1960

These words had a prophetic ring, but when Willard F Libby received the Nobel Prize, no one could have imagined the multitude of disciplines which, four decades later, are affected by his discovery. Some idea of their variety and range was reflected in the sessions offered by the 17th International Radiocarbon Conference held in Israel last June: archaeology, geophysics, and geochemistry, environment past and present, global change, glaciology, hydrology, oceanography, geology.... Radiocarbon dating has rewritten human history, changed the way we see the oceans, rocks, soils of our earth, and given new insight on solar activity.

If, as Louis Pasteur wrote, "chance favors the mind that is prepared," Libby was well prepared for the discovery that is still leaping across interdisciplinary boundaries.

\section{Linking 'The Two Cultures'}

Today, collaboration between scientific branches is taken for granted, and even between scientific and humanist disciplines. This was not always the case. In 1959, at Cambridge University, British physicist and writer, C P Snow, compared "literary intellectuals" and "natural scientists" and found them to be separated by boundaries of deep mutual suspicion and incomprehension. Humanists "give a pitying chuckle at the news of scientists who have never read a major work of English literature...," yet how many of these "literary intellectuals" could describe the Second Law of Thermodynamics - the scientific equivalent of reading a work of Shakespeare (Snow 1993)? The Cambridge lecture became a book, The Two Cultures, which has had over 30 editions.

At the University of California, Berkeley, where Libby worked for 14 years as a student, then as a member of the faculty, he regarded Gilbert N Lewis, Dean of the College of Chemistry, as his men-

1The author's forthcoming book, Pharaohs and Fallout, is a biography of Willard F Libby.

${ }^{2}$ Photo by Fabian Bachrach circa 1952. AEC-54-5123-DOE. 
tor. A physical chemist widely known for his work on thermodynamics, his unorthodox views earned him the label of enfant terrible, a label in which Lewis took pride. He regarded himself fortunate to have been home-schooled, thus escaping a formal education in his early years (Hildebrand 1947). Decades before The Two Cultures was published, Lewis had been a bridge between them, having obtained a BA in English Literature and a PhD in Chemistry. His books, written in an elegant literary style, reflect his open-minded, broad culture. In his famous College of Chemistry, Lewis overturned entrenched traditions, such as the sacrosanct separation of disciplines. When Libby undertook to build a Geiger counter for Senior Honors, Lewis made no objection; physical chemistry, he liked to say, is whatever "I am interested in" (Arnold 1981). His staff shared this approach and, for the rest of his life, so did Libby.

During World War II, at the secret SAM (Substitute Alloy Materials) Lab at Columbia University, Libby contributed to the success of the gaseous diffusion method for the separation of the uranium isotopes. The making of the atomic bomb was a huge enterprise that established new patterns of collaboration between government and different branches of science and engineering. After the war, Libby joined the newly formed Institute for Nuclear Studies (now Fermi Institute) at the University of Chicago, along with other scientists who had worked on the Manhattan Project. They continued the wartime spirit of collaboration, and unfamiliar fields beckoned. For Harold Urey, winner of a Nobel Prize for his discovery of deuterium, and ex-director of the SAM Lab, what beckoned was... the Moon. For Libby, what beckoned was a time clock capable of dating human history.

\section{APPLICATIONS AND METHODOLOGY}

Radiocarbon dating was "born interdisciplinary". Since the Berkeley years when M Kamen and S Ruben, looking for a useful tracer, found man-made ${ }^{14} \mathrm{C}$, thanks in part to his version of a Geiger counter, Libby had pondered on the probable half-life and possible uses of the "natural" nuclide assumed to be produced by cosmic radiation. His deductions about its geochemistry followed logical steps: Formed in the stratosphere and distributed world-wide for uptake into the biosphere, the concentration of ${ }^{14} \mathrm{C}$ would remain constant in an organism so long as it lived; at death, the amount remaining - disintegrating at the immutable rate of radioactive bodies-would be an accurate clock of time elapsed. In Chicago, with the help of Ernest Anderson and James Arnold, Libby set out to prove his hypothesis. Their work entailed a blending of many disciplines: nuclear and cosmic ray physics, atmospheric chemistry, meteorology, biochemistry, geochemistry, and archaeology (E C Anderson, personal communication 2000). Libby's deductions were found to be accurate-on two conditions: "If the cosmic radiation has remained at its present intensity for 20,000 or 30,000 years, and if the carbon reservoir has not changed appreciably in this time..." (Libby 1955).

There is usually a time lag - perhaps a decade_- "for a technique to achieve maturity in one field and then jump disciplinary boundaries..." (Davis 1992). Libby's still immature technique began jumping boundaries almost immediately as archeologists, anthropologists, and geologists were all eager to try the new dating method. Motivation was a factor, and for some (i.e. earth sciences), the relatively large sample size required at first was not the deterrent that it was for other branches. The proliferation of disciplines using ${ }^{14} \mathrm{C}$ dating is largely due to improved methods and equipment. First, the gas and liquid scintillation counters replaced Libby's initial solid carbon method, then accelerator mass spectrometry (AMS) made possible the dating of sub-milligram samples at greater speed. Thus, minute samples of the Dead Sea Scrolls and the Shroud of Turin could be dated by AMS, establishing links with theology. Adding to the increased number and range of disciplines is the recent research and improved techniques using carbonaceous samples such as bone, shell, blood, and pollen, which previously could not be ${ }^{14} \mathrm{C}$ dated with any degree of accuracy. When discrepan- 
cies began to occur between ${ }^{14} \mathrm{C}$ and historical dates, it put Libby's method in doubt, but even this ultimately contributed to "the thinking in so many fields of human endeavour." Cosmic radiation, it was determined, had not remained at its present intensity, and the carbon reservoir had changed. In 1958, Hessel de Vries was the first to provide evidence for atmospheric ${ }^{14} \mathrm{C}$ fluctuations, later found to be caused by changes in the geomagnetic dipole, modulation by the magnetic field in the solar wind, and changes in the carbon cycle. Possibly, too, by solar flares and supernovae. These studies, and the resultant calibration with dendrochronology, led to applications in geophysics, solar physics, and astrophysics (Damon 2000).

\section{Benchmarks in Knowledge: Who Came First?}

Libby's deep interest in the arrival of early humans in the New World probably was initiated with the dating of the Two Creeks Forest Bed at Kimberly, Wisconsin, which dramatically changed the time of the last southerly advance of the ice sheet: not 25,000 years ago, as had been assumed, but about 10,000 years ago (Libby 1955). This was corroborated by subsequent ${ }^{14} \mathrm{C}$-dated evidence of early habitation on this continent.

Two findings in New World archaeology stand out for their challenge to long-held theories regarding migration across the Bering Strait. The much-contested bones of Kennewick Man pose the question: Who were the first immigrants across the Bering Strait? What did they look like? (Slayman 1997). When artifacts unearthed near Monte de Verde, Chile were determined to be 12,500 years old, predating by some 1300 years what had been seen as the oldest human habitation in the Western Hemisphere at Clovis, New Mexico, it upset some basic premises of the Bering Strait theory (Meltzer 1997). The land bridge caused by global cooling lasted from 14,000 to 12,000 years ago; the previous such opportunity was probably 22,000 years ago. "This meant," said team member D J Stanford of the Smithsonian, that "they either had to go like hell to get to South America, or they simply came in earlier." Or did they come by boat? (Suplee 1997a).

D F Dincauze of the University of Massachusetts called the Monte Verde find "a new benchmark in knowledge" (Suplee 1997a). This could be applied to many of the discoveries that have been ${ }^{14} \mathrm{C}$ dated, including the following examples.

\section{An Unexpected Union}

The 24,500-year-old skeleton of a boy found in Portugal's Lapedo Valley held a great surprise for paleontologists. The child's genetic heritage suggested that he was a hybrid of Neanderthal-supposedly extinct before his birth—and Homo Sapiens (Bower 1999).

\section{Farming Dated by the Cucurbita Pepo}

A cave near Oaxaca, Mexico, put ancient farming in a new light. ${ }^{14} \mathrm{C}$ dating of seeds and other plant remains of a cultivated crop-not corn, as might have been expected-but a species of squash, cucurbita pepo, extended plant domestication back to about 10,000 years, over 4000 years before the earliest evidence of maize or bean crops (Smith 1997). This made the finding contemporary with the dawn of agriculture elsewhere, but with a difference. "In the Middle East," said K V Flannery of the University of Michigan, "permanent village life began even before agriculture" because they had plenty of wild barley and wheat. "In Mexico, however... the first villages don't show up until around 1500 B.C." long after this new evidence of farming. Their wild plant, corn, was "an unappetizing thing with a tiny spike of seeds...". Agriculture, then, did not develop uniformly; different plants resulted in different stages of farming in the New World and the Old (Suplee 1997b). 


\section{World's Oldest Woven Cloth}

Another "benchmark" was a semi-fossilized scrap of cloth found adhering to a piece of antler in Cayonu, Turkey. ${ }^{14} \mathrm{C}$ dating found it to be 9000 years old, pushing back the development of woven textile 500-1000 years (Broadway1993).

\section{World's Oldest Paintings}

The history of art is one of the non-scientific disciplines now using ${ }^{14} \mathrm{C}$ dating. Microorganisms sealed into ancient rock engravings or paintings can be dated by AMS using improved carbonextraction techniques (Howard 1996). The Oxford Radiocarbon Accelerator Unit in England, which analyzes around 100 dates a year on art history, reports: "The method is not very effective in the last five centuries... much more directly useful for earlier periods" (ORAU). With cave paintings, it has brought dramatic results. Two recent cave findings in southern France predate those at Lascaux, ${ }^{14} \mathrm{C}$ dated in 1950. The Cosquer Grotto, near Marseille, accessible only by a deep underwater tunnel, has vast, partly submerged chambers decorated with paleolithic engravings and paintings depicting over one hundred animals, mostly horses. These were found to be 19,000 BP, about two thousand years before those of Lascaux. An earlier phase, around 27,000 BP, is represented by outlines of hands stenciled by projecting red or black coloring (Info-France 1997). Even more ancient renderings of animals, skillfully executed, are in the Chauvet Grotto near Vallon-Pont-d'Arc in the Ardeche. In one chamber is painted a strange creature with the torso of a bison set on human legs. Over 30,000 years old, these are the oldest known paintings in the world. A benchmark in the history of art, this Grotto is "proof that Homo Sapiens had acquired very early the mastery of drawing" (Agence France-Press 1997).

\section{Dating Earthquakes}

Jumping across to paleoseismology, ${ }^{14} \mathrm{C}$ dating is applied to the study of earthquakes by digging a hole on an active fault to locate a rapid "slip." Dating the soil can determine approximately when this slip occurred, a valuable guide to the history of a particular earthquake (P Silver, personal communication 2000). The technique was used successfully in 1968 in Canada's Saguenay region to date a 17 th century earthquake (J Y Chagnon, personal communication 2000).

\section{Environmental Doctor}

During the Cold War, Libby was appointed to the Atomic Energy Commission (AEC). He directed a secret AEC project on the effects of fallout from nuclear bomb tests. "Project Sunshine" was the first study on worldwide stratospheric mixing. The results had vast implications on meteorology, oceanography, and air pollution (Libby 1957). In 1959, he returned to the West Coast, to the University of California at Los Angeles, where he became director of its Institute for Geophysical and Planetary Physics. At UCLA, ${ }^{14} \mathrm{C}$ dating was not Libby's main focus. "I don't want to be the pope of archaeological dating," he used to say (Arnold 1992). There was still much to explore: environmental problems, space chemistry, meteorology, oceanography-to which was applied Libby's method for dating waters with tritium ${ }^{1}$. He served on federal and state commissions on air pollution, and initiated a multidisciplinary $\mathrm{PhD}$ program for future environmentalists that included chemistry, physics, geology, hydrology, geophysics, biology, and botany. There was a major role for chemistry, he

${ }^{1}$ Of course, natural cosmic-ray induced radiocarbon is also of interest in astronomy, meteorology, climatology, etc., as it represents an important geophysical parameter-providing information on solar activity and changes in the geomagnetic polar field. However, I do not list these applications here, as they do not directly involve the practice of radiocarbon dating. 
felt, in the brand-new space research. He collected meteorites and was one of the first to perceive their potential value for transmitting information from outer space. With the support of President John F Kennedy, he obtained funds from NASA to build the UCLA Space Center.

\section{CONCLUSION}

Edward Deevey, himself adept at many branches of science, felt that "BP" should stand for "Bill's Practice," and he posed this question (Deevey 1984):

From Lascaux to the pharaohs and Teotihuacan; from the Glacier Peak eruption to Ilopango and Tambors; from tundra to rain forest, from ground sloths to goats; from neutrons to sunspots, precessions, and magnetic reversals; has any branch of historical science, any sector of the atmosphere-lithosphere-biospherecryosphere system remained untouched by some application of Libby's momentous discovery?

\section{REFERENCES}

Arnold JR. 1981. Willard F. Libby: Biographical Memoirs. American Philosophical Society. p 608-12.

Arnold JR. 1992. The early years with Libby at Chicago: a retrospective. In: Taylor RE, Long A, Kra R, editors. Radiocarbon after four decades: an interdisciplinary perspective. New York: Springer-Verlag. $\mathrm{p} 8$.

Berger R. 1982. Libby's UCLA radiocarbon laboratory: contributions to archaeology. In: Taylor RE, Long A, Kra R, editors. Radiocarbon after four decades: an interdisciplinary perspective. New York: Springer-Verlag. p 421.

Bower B. 1999. Fossil may expose humanity's hybrid roots. Science News 155(19):295.

Broadway W. 1993. Earliest woven cloth dated to 7,000 B.C. Washington Post. 26 August 1993.

Damon PE. 2000. Radiocarbon calibration and application to geophysics, solar physics, and astrophysics. Radiocarbon 42(1):1-12.

Davis JC. 1992. New biomedical applications of radiocarbon. In: Taylor RE, Long A, Kra R, editors. Radiocarbon after four decades: an interdisciplinary perspective. New York: Springer-Verlag. p 580.

Deevey ES. 1984. Zero BP plus 34: 25 years of radiocarbon. Radiocarbon 26(1):5-6.

Hildebrand J. 1947. GN Lewis: Obituary notices, Royal Society; reprinted NAS.

Howard K. 1996. Artful dating. Scientific American 274(6):24.
Libby WF. 1955. Radiocarbon dating. 2nd edition. Phoenix edition 1965

Libby WF. 1957. Isotopes in meteorology. US Department of Energy 1562/131/5, 1512-1513.

Nobel Committee for Chemistry 1960. Westgren A, Chairman. Presentation speech.

[ORAU] Oxford Radiocarbon Accelerator Unit. 2000. 6 Keble Road, Oxford OXI 3QJ, United Kingdom.

17th International Radiocarbon Conference. 2000. Organizing Committee bulletin.

Slayman AL. 1997. A battle over bones. Archaeology 50(1): 16 .

Smith BD. 1997. The initial domestication of Cucurbita pepo. Science 276(5314):932-3.

Snow CP. 1993. The two cultures. Cambridge: Cambridge University Press. Canto Edition.

Suplee C. 1997a. Find may rewrite Americas' history. Washington Post. 11 February 1997, A1.

Suplee C. 1997b. Proof of ancient farming found. Washington Post. 9 May 1995. A-22-2.

Taylor RE, Long A, Kra R, editors. 1992. Radiocarbon after four decades: an interdisciplinary perspective. New York: Springer-Verlag. p 596.

Taylor RE. 2000. Fifty years of radiocarbon dating. American Scientist 88:60-7.

Wilford J. 1999. Discovery suggests humans are a bit Neanderthal. New York Times. 25 April 1999. 